\title{
El tercer milenio como desafío para la Iglesia
}

\section{Cristianisme i Justícia*}

Una mirada atenta a la historia del segundo milenio quizá nos permita subrayar otros errores similares... ¿Cómo callar después de tantas formas de violencia perpetradas en nombre de la le? Guerras de religión, tribunales de la inquisición y otras formas de violación de los derechos humanos... Es necesario que también la Iglesia, a la luz del Vaticano Il, vuelva a analizar por iniciativa propia los aspectos oscuros de su historia, valorándolos a la luz de los principios del evangelio... Ello podría ser una de las virtudes del próximo jubileo. Dicho examen no perjudicará en modo alguno el prestigio moral de la lglesia, que incluso resultará reforzado por los testimonios de lealtad y de coraje en el reconocimiento de los errores cometidos por sus hombres y, en cierto sentido, en su nombre.

Al linal de este segundo milenio debemos hacer un examen de conciencia: ¿Dónde estamos? ¿A dónde nos ha conducido Cristo? ¿Dónde nos hemos desviado del Evangelio?

Juan Pablo II'

\section{Introducción: síntomas para un diagnóstico}

El destino eclesiológico del siglo XX ha sido paradójico. Podemos diseñarlo en unas cuantas líneas.

* Publicado en el Cuaderno 91, agosto de 1999.

I. El primer texto procede del memorial enviado a los cardenales en la primavera de 1994: Riflessioni sul Grande Giubileo dell'anmo duemila. El segundo, de una entrevista concedida al periodista polaco Jas Gawronski, citada por L. Accattoli, Mea culpa. Barcelona 1997, p. I1. 
1. En sus comienzos anunciaron algunos que iba a ser "el siglo de la Iglesia". Esta vivió no obstante, hasta Pío XII, en lo que fue calificado como "espléndido aislamiento". Con el concilio Vaticano II tuvo lugar uno de los mayores acontecimientos eclesiológicos de toda la historia del cristianismo. En él pareció que la Iglesia se convertía "ella misma en motivo de credibilidad" como había soñado cien años antes el Valicano I.

Pero el siglo concluye con una aguda crisis de la institución eclesial, que ha sido calificada como "invierno" o como "involución". Estas palabras aluden a una política que pretende salir de la crisis no afrontando los problemas con fe, sino meramente a partir de "profecías de calamidades" y de actos de autoafirmación o huidas hacia el pasado. Tales conductas sólo consiguen convertir el soñado "motivo de credibilidad" en "excusa de increencia".

Resultado de esas políticas es que, por un lado, la institución no parece capaz de convertirse en asiálica o en africana, mientras el centro de la historia va desplazándose hacia el Asia. Por otro lado, tampoco parece haberse dado una verdadera inculturación de la instilución eclesiástica en la modernidad (o postmodernidad) occidental y, quizá por eso, se produce en occidente un éxodo masivo y silencioso, que no logra verse frenado ni por la crisis a que parece estar llegando el paganismo occidental, ni por el despertar de nuevas búsquedas religiosas, o por eso que se ha llamado "una nueva oportunidad evangelizadora".

Es cierto que la "pérdida de credibilidad" afecta hoy a todas las instituciones (gobiernos, partidos políticos, organismos internacionales...). Pero ello no exime a la Iglesia de examinar su propio problema y buscar sus causas.

2. ¿Es el diagnóstico anterior demasiado pesimisla? Creemos que sólo en parte. Porque tampoco cabe negar que, después del Vaticano II, ha ido apareciendo un nuevo tipo de creyente que ya no es resultado de una presión sociológica y de una adoctrinación infantil, sino fruto de un verdadero encuentro con Jesucristo y de una madura decisión de fe. Como también se ha ido produciendo una creciente desvinculación entre muchos sectores eclesiásticos y los grupos socialmente conservadores.

No obstante, es precisamente entre esos cristianos "adultos" donde se da muchas veces la mayor decepción ante la institución eclesiástica. Con ello surge el peligro de que el sentido eclesial (que es intrínseco a la fe cristiana y al seguimiento de Jesús) vaya quedando relegado a sólo grupos "residuales", fundamentalistas y ajenos a la marcha de la historia.

Con gran probabilidad hay que señalar el año 1968 y, en concreto, la aparición de la Humanae Vitae como una verdadera bomba en la línea de flotación de la credibilidad eclesial, desencadenante de una crisis de confianza que, luego,

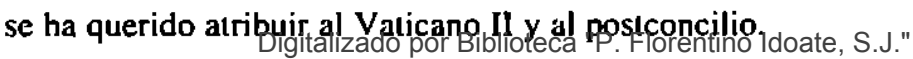

Universidad Centroamericana José Simeón Cañas 
3. Esta es nuestra siluación. Podría objetarsc con razón que el mero descenso numérico, en un mundo cada vez. más contrario a aquello que san Pablo califícaba como "la sabiduría de la cruz", no es en sí mismo ningún índice alarmante.

Esta objeción merece ser alcndida. El misıno pueblo de Dios del Antiguo Testamento conoció épocas análogas a la de la "cristiandad" medieval, y otras épocas en las que sólo parecía existir en la fídelidad de "un resto" que. según la Biblia, acabaría salvando a todo el pueblo. Los primeros cristianos, a los que hoy sucle apelarse tantas veces como punto de referencia en el que debería mirarse la Iglesia del siglo XX, tampoco gozaron de mucha credibilidad sociológica.

Y si del siglo I pasamos al siglo XX, nos encontraremos con el caso de América Latina donde, más frecuente que la pérdida de la fe típica del primer mundo, sigue siendo el "cambio de Iglesia". Ahora bien, esos cambios tienen causas tan tremendamente variadas que parece imposible erigirlos en malerial unívoco de análisis.

Grandes terratenientes caletaleros de Guatemala se nicgan por principio a contralar (¡y por sueldos de hambre!) mano de obra "calólica" que puede estar concientizada de sus derechos por la teología de la liberación: en estas situaciones, que no dejan alternativa, cs una tentación demasiado fuerte el dejar la Iglesia y pasar a alguna secta para poder mulvivir. En olros lugares, micmbros de antiguas "comunidades eclesiales de base" han pasado hoy a algunas sectas por no poder soportar el rechazo global de la jerarquía y por la necesidad de sentirse en una institución donde encuentren calor y no exclusión (que de ésla ya les da bastante la sociedad). En otros lugares de América Latina no es infrecuente que miembros de comunidades "carismáticas" acaben siendo caldo de cultivo para alimentar sectas espiritualistas de origen norteamericano. Ha habido también candidatos al ministerio eclesial que acabaron ordenándose en alguna comunidad protestante, porque no sc sentían capaces para el celibato...

Las causas son tan tremendamente diversas, que no parece que se pueda hablar de un mismo síntoma.

4. Parece pues que la Iglesia no debería alarmarse por principio ante la pérdida de lugar social. Pero sí debe preguntarse si ese descrédito es debido a que ella -al igual que Pablo- "no quiere saber en este mundo más que a Cristo crucificado" ( 1 Cor 2, 2), o si es debido a esa olra ley de la historia por la que las instituciones religiosas acaban por "extinguir al Espíritu" (ITes 5, 19), en lugar de encarnarlo, y desencadenan así la aparición de "profctas", los cuales suelen morir a manos de la institución, pero acaban por redimirla. Jesús inismo es presentado por los evangelistas como el primero (y "más que profela") de todos ellos.

Este es un dilema central. En buena lógica. deberíamos añadir que, quienes optan por la primera alternativa como respuesta a ese dilema, -es decir, que el

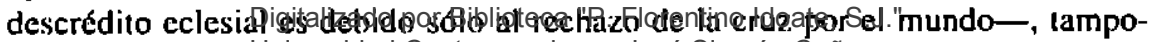
Universidad Centroamericana José Simeón Cañas 
co deberían preocuparse demasiado por su pérdida de credibilidad, ni tratar de contrapesarla a base de proyectos de reconquista, ni de operaciones mediáticas superficiales, que, en el fondo, quizá sólo retlejan una negativa a abordar la segunda alternativa del dilema propuesto.

En cambio, quienes dan vigencia a la segunda alternativa (sin negar la primera) lo hacen porque es un hecho conocido que, a lo largo de este segundo milenio, la institución eclesial se negó demasiadas veces a escuchar las voces que reclamaban una reforma radical in capite et in membris (en la cabeza y en los miembros), sin aprender de las crisis a que la había ido llevando su situación de poder ${ }^{2}$ y desautorizando sistemáticamente todas las voces que pedían la reforma (entre las cuales figuran muchos santos hoy canonizados). Hasta que la Iglesia se encontró con la ruptura de Lutero que la llevó a una "contra-reforma" ya tardía, hecha desde el trauma de la división y desde el miedo, y mucho más atenta a protegerse "del otro" que a escucharlo. (Naturalmente, puede censurarse la ruptura de Lutero desde un punto de vista teológico. Pero lo que no cabe negar es que, desde un punto de vista histórico, fue la obstinada negativa a la reforma lo que acabó provocando aquella ruptura.)

5. La Iglesia llega, pues, al tercer milenio dividida, en minoría, con credibilidad mermada y con cierta perplejidad interna. Pero también con brotes muy importantes de vida y de calidad cristianas (una fe más libre y más respetuosa. con mayor experiencia espiritual, mayor seguimiento de Jesús y mayor opción por los pobres...), los cuales pueden dar frutos antes desconocidos.

Y esa Iglesia va a enfrentarse a un mundo también en crisis, y del que puede ser útil esbozar algunos rasgos:

-Un mundo muy unificado técnica y económicamente y, a la vez, muy plural en culturas, épocas históricas e ideas.

- Un mundo sin fundamentos absolutos para la convivencia. Con el peligro de que, al faltar el Fundamento Absoluto, cada cual absolutice su parcialidad, y quiera concebir la convivencia a partir de ella. De donde surgirán mil tentaciones de racismos, xenofobias, imperialismos o fundamentalismos violentos.

-Un mundo con clara conciencia de libertad y de su mayorfa de edad. Y, por ello,

-Un mundo que valora la democracia y busca formas de control del poder. Y donde los esfuerzos por la plena liberación e igualdad de la mujer deben scr destacados como una de las más claras señales del Espíritu -como ya señaló Juan XXII hace 35 años (cfr. Pacem in terris, nח. 39-45).

2. Cautividad de Avignon, cisma de occidente, aparición de disidentes que invocaban al evangelio comoDiaitolizad Qudisideliptian "P. Florentino Idoate, S.J."

Universidad Centroamericana José Simeón Cañas 
-Un mundo plagado por la injusticia, según Naciones Unidas. Si hace dos siglos las diferencias entre paises ricos y pobres llegaban al doble, hoy son del orden de las sesenta veces. Esa dinámica va a más. Y esas diferencias son más perceptibles que nunca por la invasión de la propaganda y de los inedios de comunicación social. Ello pucde llevar a mil reacciones de los desesperados, que irán desde migraciones masivas imparables hasta violencias.

-Un mundo donde todo sc comercializa y donde hasta lo más sagrado es simple material de mercado.

-Un mundo cansado de palabras e incrédulo frente a todos los grandes sistemas explicativos globales: pero prolundamente sensible a la biografía concreta cuando ésta transpira coherencia y grandeza humana.

—Un mundo con una especic de "cáncer" ccológico; y portador de una especie de VIH armamentisla o nuclear, que no sabemos cómo puede acabar.

- Un mundo profundamente escéptico sobre sus propias posibilidades de salvación, aunque deseoso de ellas; pero sólo dispuesto a atenderlas si no exigen demasiado precio ni parecen demasiado honitas.... Y donde el rebrote positivo de movimientos de solidaridad choca muchas veces con una profunda sensación de impotencia...

6. Las observaciones anteriores nos parece que -a la hora de hacer un diagnóstico- devuelven toda su vigencia a las palabras con que Juan XXIII abrió el concilio Vaticano Il, y en las que alertaba contra...

insinuaciones de almas que, a pesar de su ardiente celo, no están dotadas de suficiente discreción y mesura, que no ven en los liempos modernos más que la prevaricación y la ruina. Que van diciendo que nuestra edad ha empeorado respecto a las edades pasadas, y se comportan como quienes nada tienen que aprender de la historia, la cual sigue siendo maesira de la vida... Nos sentimos obligados a disentir de esos profetas de calamidades, que anuncian acontecimientos siempre infaustos. como si nos acechase el fin del mundo'

Esa "discreción y mesura", esa serenidad y falta de miedo, y esa capacidad para aprender de la historia, las va a necesitar la Iglesia en el próximo milenio. Quizá, pues, todas las consideraciones anteriores puedan llevarnos a la aceptación serena de la pregunta: ¿qué le pasa hoy a la Iglesia? $O$ aún mejor: ¿está Dios pidiendo algo a su lglesia? Y en este caso, ¿qué es lo que le pide?

Todos los cristianos deberíamos hacernos este tipo de preguntas, sin pensar que sólo pueden ser fruto del resentimiento o del afán de crítica estéril. Y pidiendo a Dios que nos libere de ese reflejo condicionado de todos los hombres del poder, que siempre reaccionan ante los hechos en defensa de sus propios

3. Documentos dePcoialią) BACBiblietsfa "P. Florentino Idoate, S.J." 
intereses institucionales, y que sólo saben ver en cualquier demanda de relorma un ataque personal. En todo caso debería servirnos de lección lo que ocurrió con Jesús. Pues somos seguidores de un hombre que fuc denunciado y llevado a una cruz inlame e inlamante, precisamente por las autoridades religiosas -en aquel momento legítimas- del pueblo de Dios, que se sintieron molestas por sus interpelaciones proféticas y sus críticas al sistema religioso (cfr. Mt 23 y Mc 11 , 15-18). Le hicieron la vida imposible -a él, primero, y a sus seguidores, despućs- pensando que hacían un obscquio a Dios (cfr. In I6,2) y al pueblo (cfr. In 11. 48).

7. En las escasas dimensiones de este escrito, será imposible abordar a cabalidad un problema tan amplio. Su mejor fruto sería que, en lo sucesivo, el problema de la ecclesia semper reformanda esté perpetuamente planteado', y se viva la fe teniéndolo siempre ante los ojos, pero desde aquella serenidad del Espíritu, que "hace nuevas todas las cosas".

Si a alguno le parecen demasiado críticas las páginas siguientes, será bueno aclarar que no nos mueve a redactarlas ningún a aán de dar lecciones o de imponer nuestras opiniones particulares. Sabemos bien que, si se tratara de "arrojar la primera piedra" no estamos nosotros sin pecado para poder hacerlo (cfr. Jn 8, 7). Nos mueven más bien estas dos cosas: a) la convicción de que la misión de la Iglesia no es crear "hombres del stablishment", sino seguidores de Jesús. Y b) saber que también nosotros somos simplemente unos perdonados y podemos llamar a Dios Padre, y que ésa es la obra del Espíritu de Dios en nosolros (cfr. Rom 5, 5 y 8, 3). El perdón es una fuente de unidad, precisamente porque a todos nos hermana el pecado.

$Y$, ya que hemos hablado de la necesidad de una "credibilidad práctica", vamos a sistematizar las reflexiones que siguen en torno a esas cuatro notas de la Iglesia (una, santa, católica y apostólica), que todos proclamamos en el credo como señales de la verdadera Iglesia, y como fruto de la acción del Espíritu de Dios en ella.

\section{Que la Iglesia vuelva a ser una}

La unidad de la Iglesia es, para Jesús, condición de su credibilidad: "que todos sean uno... para que el mundo crea" (cfr. Jn 17, 21).

Esto nos puede dar una idea de la importancia de la tarea ecuménica de cara al próximo milenio. La voluntad de Dios sobre su Iglesia se expresa mucho más en el imperativo de unidad que en la pervivencia de una determinada estructura,

4. Pablo VI pedía a la curia romana, ya en 1963, que esluviera siempre en la vanguardia de este planteamiento: la Curia siessa all'avanguardia di quella riforma, di cui la

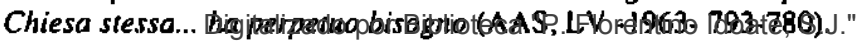


por Inucho que pretendan alerrarse a ella los responsables de la institución eclesiástica. En este sentido, cl esfuerzo ecuménico aspira a manifestar la "Iglesia de la trinidad" como la definió el Vaticano II: "una muchedumbre reunida por la unidad del Padre y del Hijo y del Espíritu Santo" (LG 4).

Esa unidad es la que ha sido desligurada por las divisiones. $Y$ por eso, sin la unión de las iglesias, el mensaje cristiano del que cllas son responsables no podrá menos de aparecer de modo inevitablemente unilateral y, por ello, deformado. La división de las iglesias debe ser mirada como la mayor, quizá, de esas culpas que el Vaticano II confesó como imputables a los creyentes en la aparición del ateísmo moderno (GS 21).

En efecto, si las iglesias de la reforma -desde la pregunta por la justificación- recuperan la benevolencia del Dios Padre, que es a la vez origen de todo y "justificador del impío" (supremacía y misericordia), la Iglesia católica ha conservado más el legado cristológico en el que la palabra se hace efectivamente "carne" de esta historia, y planta su tienda en ella. Por eso, conserva virtualidades imprescindibles para rescatar los aspectos comunitarios de la fe y los aspectos estructurales del pecado, junto a la primacía de los pobres cristológicamente motivada, pero también junto al peligro de sacralizar todo lo que es meramente institucional. A su vez, las iglesias de oriente han conservado mejor la tradición del Espíritu sin el cual la gracia se volverá barala, y la entrada en el mundo se convertirá en esclerosis; pero esa tradición amenaza con ir a dar en un espiritualismo estéril, sin la incorporación "del Padre a través del Hijo": del compromiso amoroso con este mundo que es, a la vez, creatura de Dios, hostil a Dios y perdonado por Dios.

En este contexto de divisiones, es admirable la insistencia con que Juan Pablo II ha venido repitiendo que la Iglesia debe saber pedir públicamente perdón por sus pecados pasados... y presentes. Ese perdón no ha de limitarse a los judíos. En las dos grandes fracturas que ha sufrido la Iglesia en este milenio que ahora clausuramos (la ruptura de oriente y la ruptura de Lutero), tuvo un gran porcentaje de culpa la Iglesia romana. Y eslo puede decirse sin mitificar a ningún reformador, ni desconocer las arbitrariedades y la falta de espíritu que hubo en las otras partes del conflicto.

\section{Unidad en el perdón}

En efecto; la ruptura con oriente (1054) comenzó en realidad más de un siglo antes. Roma, que acababa de acceder al poder político de los papas, se sobrepasó en su papel de arbitraje entre Focio e Ignacio (que se disputaban la sede de Constantinopla), tratando de decidir más bien por intereses políticos, como pretensiones sobre tierras del Ilírico y la disputa con Constantinopla por la jurisdicción sobre Bulgaria... Estos intereses de poder deformaron el arbitraje. Hubo de

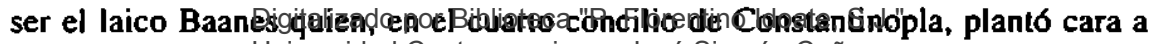
Universidad Centroamericana José Simeón Cañas 
los legados papales, negándose a firmar un texto de condena de Focio sin que antes hubiera sido escuchado éste. La adición del filioque al credo es teológicamente legítima, pero se hizo desde occidente sin respetar el derecho vigente, que prohibía añadir nada al credo de Nicea y Constantinopla. Las relaciones estaban ya envenenadas antes de la ruptura.

Algo parecido ocurre con la ruptura de Lutero. Los casi cien años que van desde el tinal del concilio de Basilea al V de Letrán (que concluye en I517, sólo un año antes del estallido de Lutero) tejen un siglo de negativa de los papas a las reformas que toda la Iglesia venía reclamando desde que logró salir del traumático cisma de occidente. Como dice un historiador de la Iglesia, "Roma impidió la reforma católica de aquel momento y, poco después, en carnbio, tuvo que afrontar la reforma protestante"s.

Las rupturas, por tanto, habían ido preparándose por una política obsesionada con la acumulación de poder, y caracterizada por la negativa a atender las demandas de la realidad.

Y no recordamos estas cosas por el gusto de reabrir heridas pasadas, sino porque el Vaticano II señalaba como primeros principios del ecumenismo la reforma de la Iglesia y la conversión del corazón (cfr. UR 6 y 7). Lo hacemos, por tanto, para subrayar la necesidad del perdón mutuo y, tras ella, el reconociiniento de las dificultades que varios siglos de historia separada y enemistada han de haber acumulado.

Eslo ayuda a comprender mejor un dato que brola también de la eclesiología del Nuevo Testamento: la unión de los cristianos no debe ser concebida como una uniformidad dictada desde Roma, sino como una comunión verdadera y eficaz dentro de la pluralidad de diversas tradiciones: por eso: "no hay por qué buscar una mayor unidad ecuménica de la Iglesia en el futuro, partiendo del modelo de unidad que existe hoy dentro de la Iglesia católica". Porque el Espíritu no es solamente principio de unidad, sino de libertad y de diversidad. Por ello, las iglesias que han quedado testimoniadas en el Nuevo Testamento para que pudieran servir de punto de referencia normativo (canónico) para toda Iglesia que quisiera ser fiel al proyecto de Jesús (es decir, al "reino de Dios") y así pudiera merecer el nombre de "cristiana" como "denominación de origen", reflejan un pluralismo teológico y estructural muy nolable y enriquecedor?.

5. K. Fink, en el Manual de historia de la Iglesia, Barcelona. 1973, IV, p. 752.

6. M. Kehl. La Iglesia, Salamanca, 1996, p. 349. El autor está comentando unas palabras del cardenal Ratzinger. Sugerencias prácticas más concretas las había en el libro de K. Rahner y H. Fries, La unidad de las iglesias una posibilidad real, Barcelona, 1987.

7. Ast lo indica un gran especialista católico en Nuevo Testamento que fue miembro de la Pontificia Comisión Bfblica hasla poco antes de su muerte. Ver R. E. Brown, Las

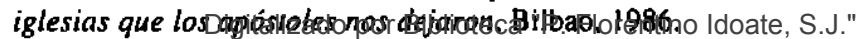

Universidad Centroamericana José Simeón Cañas 
Un sentimiento compartido de perdón. de misión y de servicio al mundo, que brote de la fe en un mismo Padre, en un mismo Scñor y en el mismo Espíritu. unirá a las iglesias más que las conversaciones y diálogos teologicos (tan necesarios por otro lado).

El problema que hoy resulta inás vidrioso en este campo —el del ministerio de Pedro-, lo abordaremos al hablar de la Iglesia aposı́lica. Quedémonos ahora con que a semejanza de la trinidad -y como acabamos de decir- la unidad de la Iglesia no es la uniformidad de lo mismo, sino la comunión de lo plural.

\section{Que la Iglesia vuelva a ser católica}

Ya en el primer siglo del cristianismo, el Nuevo Testamento da testimonio de una llamativa pluralidad de iglesias y eclesiologías. A propósito de este dato, se ha hecho notar muchas veces que esa pluralidad de la Escritura no se resuelve privilegiando un "canon dentro del Canon", sino que el canon bíblico reside en la totalidad del Nucvo Testamento.

\section{Kat-hólica}

Más aún, la palabra catolicidad no significaba en sus orígenes una mera totalidad geográlica", sino una totalidad de diversidades unilicadas, sin renunciar en lo posible a ninguna. Católico viene de kata-holon: "según lodos los aspectos". Es, por tanto, lo que trata de ser integrador, sin excluir nada.

$Y$ es innegable que hay cosas que son incompatibles con la verdad o con el bien y que deben ser excluidas. Pero es también innegable la tendencia humana a concebir las diversidades como incompatibilidades: esa tendencia acaba reduciendo a Dios al tamaño humano individual o grupal, y contra ella se erige la intuición "católica" de Dios.

Catolicismo podría traducirse, entonces, como omni-versalismo, que expresa un sentido de unidad mucho más difícil y más perfecto que el que sugiere la palabra uni-versal, donde la unidad parece brotar de la imposición de uno solo. Catolicismo es el afán por ese tipo de unidad imposible, que no excluye ninguna parcialidad y que se afirma como posible desde la fe trinitaria en el Espíritu de Dios, derramado "sobre toda came", y desde la fe en la encarnación de Dios en todos nuestros rasgos humanos (salvo el pecado, que sólo es la fuerza de lo inhumano). Cat-ólico es así una denominación de la que cabe sentirse orgulloso.

Pues bien, la tragedia del catolicismo actual es que ha pasado a ser denominación meramente sociológica, que sólo designa una particularidad entre otras. Más aún, no sọ́lo designa una parcialidad entre otras, sino precisamente la más

B. Que entonces todavía no se daba, y para la cual se utiliza más bien la palabra oikoumênê. 
cerrada y menos audaz: la palabra Frühkatholizismus (catolicismo primitivo) aparece en los estudios bíblicos para designar esa eclesiología más autoritaria y más asustadiza, que se encuentra en las cartas pastorales del Nuevo Testamento (primera a Timoteo y a Tito).

\section{Eclesiología insuficiente, Iglesia incompleta}

Efectivamente, la eclesiología práclica de la actual Iglesia católica está construida casi exclusivamente sobre una parte del Nuevo Testamento, que son esas cartas pastorales. No contiene nada de la eclesiología de Pablo, en sus cartas a los corintios (libertad y pluralidad, unilicadas por un único Señor y un único Espíritu). Ni tampoco de la eclesiología que se adivina a través de los escritos joánicos (donde la fraternidad y la igualdad de todos, creada por la venida del Hijo, es casi el único constitutivo de la comunidad). Ni de la eclesiología de los Hechos (cuyo primitivo "comunismo" y cuyo afán por integrar todas las particularidades convierte a la Iglesia en una comunidad alternativa, que interpela por su sola existencia). Ni de toda la eclcsiología neotestamentaria de las iglesias locales (cada una de las cuales cs ya "la" Iglesia y no una mera "parte" de ella, de modo que la llamada Iglesia universal no es una "suma" de las iglesias locales, sino la comunión de todas ellas)...

La eclesiología oficial de la Iglesia católica de hoy parece haber renunciado a todos esos ingredientes, para vertebrarse exclusivamente en torno a las cartas pastorales, junto con la idea universal de las cartas llamadas deuteropaulinas (Efesios y Colosenses), y el afán institucionalizador de Mateo (aunque sin la moderación de este evangelista, y relorzándolo con la categoría pagana del "poder sagrado", que el evangelista desconoce). De este modo, tenemos la paradoja de que la eclesiología práctica de la Iglesia católica no es, en realidad, kathólica.

Para ser fiel al Nuevo Testamento, nuestra eclesiología debe recuperar a "la Iglesia de los pobres" de Lucas, junto a la Iglesia paulina de la libertad, y junto a la Iglesia del discipulado y la fraternidad, que vivieron las comunidades del Jiscípulo amado. Esta era la dinámica del Vaticano II, cuando rechazó el esquema jurídico-vertical que se le había preparado, y comenzó delíniendo a la Iglesia como "sacramento y señal" de salvación. O cuando abandonó la calegoría de la Iglesia "sociedad" para caminar hacia una estructuración de la Iglesia como "comunión". Si abandonáramos nosotros esta dinámica del Valicano II, estaríamos en una situación semejante a aquella que hubo de combatir Pablo en su carta a los Gálatas, cuando los mismo judaizantes, que habían sido desautorizaJos en el "concilio" de Jerusalén, aparecieron predicando en Galacia contra el evangelio de Pablo.

Debe quedar claro que hablamos solarnente de "recuperar" lo perdido: no de

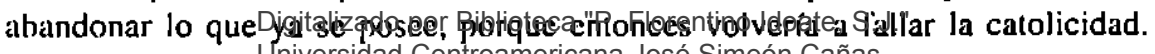
Universidad Centroamericana José Simeón Cañas 
La comunión de todas las iglesias locales en un único cuerpo de Cristo que es "la Plenitud de Aquél que va plenificándose en loda la realidad" (Ef 1, 23), será muy necesaria en el siglo XXI y en la era de la globalización. Asimismo, el proceso que va desde las primitivas comunidades carismáticas a la institucionalización de las cartas pastorales es una lección permanente contra todo anomismo barato, y es fruto tanto de la fuerza de lo real (por su opacidad y su empecatamiento), como del cambio de estrategia requerido por una Iglesia que iba creciendo cada vez más, y que se encontraba sometida a la persecución y amenazada por desviaciones que desfiguraban la identidad cristiana. De hecho, las comunidades del cuarto evangelio acabaron experimentando una dolorosa división entre ellas, y el mismo Pablo tuvo que combatir la innata tendencia humana a tomar la libertad como "excusa para el egoísmo propio" (Gal 5, 1). Quede claro, pues, que hablamos de recuperar lo que falta, sin abandonar lo positivo que ya se posee.

\section{Autoridad sí, pero integradora}

... los muchos sufrimientos... que no son causados por los búlgaros sino por los órganos centrales de la administración eclesiástica. Es ésa una forma de mortificación y humillación que no esperaba encontrar y que me hiere profundamente... La diferencia entre mi modo de ver las situaciones sobre el terreno y ciertos modos de juzgar las mismas cosas en Roma, me duele notablemente: es mi única verdadera cruz (Juan XXIII durante sus épocas de delegado apostólico en Bulgaria -1925- y en Estambul - 1944).

La Iglesia necesita autoridad c institución. Y todo cristiano debe saber que razones de unidad le exigirán más de dos veces aceptar decisiones de la autoridad que él no comparte. Pero hay que añadir que, por voluntad de Dios, ha de procurar tener esa autoridad y esa institucionalización en el mínimo grado posible, y no en las dosis máximas que parecen dar más seguridad, pero que hacen imposible la presencia de los otros faclores más evangélicos: la libertad del cristiano y la radical conversión evangélica de la autoridad en servicio. Las quejas de un hombre tan ejemplar y tan fiel como el que luego sería Juan XXIII, que encabezan este apartado, ponen de relieve una seria falta de "cat-holicidad" en el ejercicio de la autoridad por parte de Roma.

Si echamos mano de la analogía de la encarnación para fundamentar la autoridad, podremos decir que la palabra de Dios también necesitó "un cuerpo" para hacerse presente entre nosotros; pero sin que éste acabara opacando "la gloria de Dios", sino trasluciéndola ( $c f r$. Jn 1, 14). Por eso, defender la autoridad en la Iglesia significa al mismo tiempo proclamar la necesidad de su translormación, en la línea del precioso programa que Pablo se impone a sí mismo, esribiendo a los corintios (y precisamente, en una situación de grandes problemas de autori- 
dad): "no pretendo ser el señor de vuestra fe, sino el compañero de esa alegría en la que habéis ido madurando gracias a la le" $(2 \mathrm{Cor} 2,1)$.

Y todo esto puede visibilizarse aludiendo a ejemplos concretos bien recientes. Este siglo se ha clausurado con dos sínodos globales de las iglesias de Amćrica y Asia. En contraste con los primitivos concilios ecuménicos (donde Roma acudía a los lugares de las asambleas y no pretendía imponer unas conclusiones previas, sino "rccibir" dialogalmente lo que se decidiera en los concilios), esta vez han sido las iglesias de los dos continentes las que han debido desplazarse a Roma, quizás para "defenderse" contra unos textos previos, ajenos a su contexto, y que predeterminaban las conclusiones de ambos sínodos. Es inevitable comparar el decisivo influjo universal que solían tener los concilios primitivos, con la formalidad vacía de estos sínodos últimos, que casi aspiran sólo a pasar "sin pena ni gloria".

Otro ejemplo nos to ofrece el pasado documento Ad tuendam fidem, por el que se prelende que algunas cuestiones disciplinares y no dogmáticas (nombramiento de obispos, celibato presbiteral, ininisterio femenino...) queden amparadas por una posible excomunión sobre quienes se maniliestan contrarios a ellas, acogiéndose para ello a una calificación desconocida de doctrinas que no son "Je fe", ni "de/inidas", sino "definilivas". Una decisión de este tipo constituye un exceso autoritario, sólo explicable desde el miedo, y que causa a la Iglesia un daño mayor que el del mal ejemplo: el daño del ridículo. Cabría decir, con amargura, que un documento así no sirve ad tuendam fidem, sino más bien ad struendam fidem.

Hay una forma de pragmatismo eclesiológico que acaba configurando a la Iglesia de acuerdo a la "sabiduría de este inundo" (ICor I, 23) para la cual el evangelio es sencillamente "eslupidez" (1Cor 1, 23). Es el "realismo" que considera utópicas todas las voces que reclaman más igualdad y más democracia en la Iglesia o, para decirlo con el vocabulario neotestamentario (que es mucho más rico que la palabra democracia), más koinonía y más sinodalidad en la Iglesia: la primera se refiere a la comunión en el ser, y la segunda -más difícil de traducirsignilica "caminar juntos" y alude a la comunión en cl actuar.

Ese pragmatismo considera que las descripciones que hace Lucas sobre la Iglesia de los pobres son "una insensatez", consecuencia sólo de la espera equivocada de un fin del mundo inminente. A muchos biblislas del mundo rico que leen así las pinceladas ideales sobre la Iglesia en los Hechos de los Apóstoles, hay que decirles que Lucas es precisamente el autor que ha abandonado ya la espera del fin del mundo. Y que, por tanto, sus descripciones no tienen un valor exclusivamente apocalíptico sino más bien un valor histórico, es decir, tienen algo de "sacramental". Lucas ve una señal de la escatología y de la resurrección de Jesús en aquel esfuerzo porque "no hubiera pobres entre ellos" ( $c f r$. Hech 4,

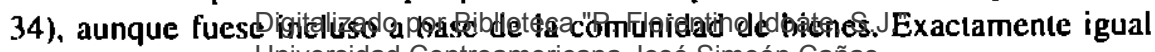
Universidad Centroamericana José Simeón Cañas 
a como la Iglesia posterior vio una señal del "más allá" en la virginidad, cuando ésta se asume como busca de un amor a todos, aunque sea renunciando al amor "mío".

En este contexto de anticipación escatológica y de simbolización de alternativas, hay que situar todo el tema de la "democracia en la Iglesia", que desarrollaremos un poco más al hablar de la santidad. Digamos ahora, para concluir, que estos esfuerzos (todo lo desesperados que se quiera) porque el espíritu evangélico empape incluso lo institucional de la Iglesia, contrastan con los siguientes rasgos con que los estudiosos del Nuevo Testamento caracterizan a aquel "catolicismo (o conservadurismo) primitivo" al que antes hemos aludido:

a) la muerte del aliento escatológico o de la anticipación de la resurrección;

b) la institucionalización creciente que pretende tener "embotellado" al Espiritu, olvidando que el Espíritu sopla donde quiere, y que la pretensión de tenerlo disponible es fruto de la tentación humana de seguridad y no de la promesa de ayuda divina. Sobre todo si se pretende disponer del Espíritu "en defensa propia";

c) la reducción de la fe a fórmulas o eliquetas que van sustituyendo a ese dinamismo de la actitud creyente que se expande hacia la esperanza y la caridad". $^{\prime \prime}$

Todos, y no sólo los responsables de la Iglesia, estamos obligados a intentar ser de veras kat-hólicos, y a no creernos únicos depositarios del verdadero cristianismo. Pero valla la pena enumerar estas afirmaciones del Nuevo Testamento, porque parccen reflejar bastantes rasgos de nuestra hora eclesial.

\section{Nueva inculturación}

Pero la principal tarea de la catolicidad en el tercer milenio no es sólo una tarea hacia dentro, sino una tarea hacia fuera. La catolicidad deberá implicar en el futuro no sólo una eclesiología más global y menos parcial, sino, sobre todo, un enorme esfuerzo de inculturación. Como escribió $\mathrm{K}$. Rahner: "el único tuciorismo permilido hoy en la vida práctica de la Iglesia es el tuciorismo de la audacia"'n.

La ruptura con lo accidental del judaísmo -simbolizado por la circuncisiónha sido una de las mayores audacias del cristianismo en su historia. Por evidente que parezca hoy, es preciso entrar en la mentalidad de aquellos hombres que

9. Según el concilio de Trento, la fe "si no se prolonga en la esperanza y la caridad. ni une con Cristo ni convierte en miembros de su cuerpo" (DS 1531).

10. Escrios de Teología VII, p. 93. Se llama tuciorismo a la opción por la mayor seguridad. 
habían recibido el rito de la circuncisión como una especic de "sacramento" delinitivo de su alianza con Dios, para comprender el vérligo que debió producir la renuncia a esa señal de identidad.

Pues bien; la Iglesia del tercer inilenio no puede imponer a todos los pueblos una especic de "circuncisión occidental". por muy prolunda y meriloria que haya sido su inmersión en la cultura grecolatina. Como Pablo, habrá de saberse deudora de todos: judíos y griegos, romanos y cscilas, asiáticos y africanos... Habrá de hacerse ella "débil con los débiles" y "toda a lodos" (1Cor 9, 19ss), cn lugar de querer hacerlos a todos "romanos". Porque, geográlicamente hablando, la Iglesia del tercer milenio ya no será curopea. Y el ceniro de la historia lutura tampoco parece que vaya a cstar radicado en Europa.

Se ha dicho inuchas veces que la inculturación no implica una identificación chata, sino una asunción transformadora. Lat inculturación del cristianismo en el mundo griego (cuando las luchas Irinitarias y cristológicas de los primeros siglos) supuso probablemente la aparición del conceplo de "persona", fuente y raíz de todo el tema de los derechos y libertades humanas, un concepto que los griegos no poseían y que supone una de las mayores aportaciones del cristianismo a la historia humana, convertido hoy casi en patrimonio común de toda la humanidad, más allá de su primitiva denominación cristiana de origen. A su vez, la asunción del aristolelisıno hacia cl siglo XIIl supuso la armonía entre religión y autonomía del mundo. que no se encuentra tan clara en otras religiones del planeta, y que está en la matriz. de todo lo que hoy calilicamos como progreso y control o conducción de la hisloria por cl hombre. nacidos precisamente en el occidente de matriz cristiana.

Pero señalar y aplaudir estas epopeyas inculturadoras no implica desconocer cuáles han sido sus precios que hoy reclaman ser superados. La excesiva contaminación con la filosofía griega hizo que, poco a poco, el poder y no el amor fuese la calegoría privilegiada para pensar a Dios. Ese germen, contrario a la enseñanza neolotestamenlaria, marcó luego a la eclesiología y relegó al ámbito intimista y no público la relación con Dios cstructurada en torno al amor. A su vez, la "autonomía de lo creado" se convirtió poco a poco en una pérdida del "norle" divino y cristológico de la creación, desligurando la relación del hombre con el mundo en un empeño "fáustico" y orgulloso, que ha acabado agotando a éste y amenazando scriamente al planeta.

Los riesgos del pasado son, pues, evidentes, y no estamos desconociéndolos ingenuamente. Pero, a pesar de ellos, la inculturación en el mundo griego (y luego, la asunción del aristotelismo) fueron tareas necesarias para la Iglesia del pasado, como lo es hoy la superación de aquellos precios, y la liberación de lo que hemos Ilamado "circuncisión occidental", para la Iglesia del futuro. EI pasado no enseña a renunciar a esas tareas autiesgadas, sino más bien a llevarlas

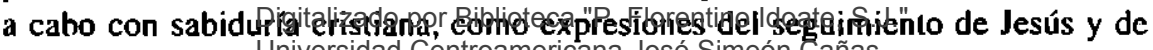
Universidad Centroamericana José Simeón Cañas 
la misión evangelizadora de la lglesia: hacerse todo a todos no es consecuencia de una le "barala", sino de la inisión de ganarlos a lodos (ICor 9, 22): pero no ganarlos para sí, sino para Cristo.

Es en este contexto donde cobra toda su importancia la alusión que antes hicimos al Asia.

\section{Asia como tarea primordial}

Propiamente hablando es en Asia donde nació el cristianismo y donde hoy es más extraño y minoritario, aunque no menos vivo. El cristianismo asiático es el que mejor ha sabido incorporar loda la novedad y cl don del Espíritu que supuso la teología de la liberación. Pcro lo ha hecho en un conlexto no occidental, y no globalmente cristiano, sino de gran pluralidad (y gran riqueza) religiosa.

Liberación c inculturación. o liberación y diálogo se abrazan así en las iglesias de Asia y encuentran allí su lugar natural. La primera descubre decisivos aportes "universales" en cl inensajc cristiano, como son el compromiso de Dios con los pobres de la tierra y con lo que Jesús llamaba "el reinado de Dios". La segunda descubre innegables limilaciones en el menaje cristiano explícito. que ha de plenilicarse a sí mismo en el encuentro con todas las "semillas del Verbo" o con las formas anónimas de "recapitulación en Cristo", que el Espíritu ha ido derramando fuera del cristianismo explícilo.

A muchos responsables eclesiásticos les va a parecer que una nueva inculturación asiática (o africana), semejante a la proeza del cristianismo antiguo en el mundo griego, implicará una infidelidad y una pérdida de identidad, semejante a la que creian ver los antiguos "judaizantes" en las iglesias paulinas. Sin embargo, Jue Pablo y no los judaizantes quien salvo al cristianismo para el fuluro.

La Iglesia del tercer milenio habrá de aprender esta lección, sin olvidar que dado que toda inculturación puede suponer precios altos-, se la hará mejor si se lleva a cabo desde el diálogo cordial y abierlo, y no desde la soledad o las obstrucciones sisternáticas contra todo esfuerzo inculturador profundo. Las tragedias que tuvieron lugar en China (en torno a Mateo Ricci), en la India (en torno a De Nobili) y en América Latina (en torno a las reducciones paraguayas) son demasiadas y no pueden volver a repetirse. Quiera Dios que, en esta hora histórica, nuestra Iglesia sepa hacer algo más que condenar teólogos asiáticos, como hizo hace años con los latinoamericanos.

Pero no es sólo tarea de Roma. Toda la Iglesia europea deberá salir de su eurocentrismo y poner muchos de sus grandes medios a disposición de ese futuro que parece que va a cocerse en Asia.

Añadamos, para concluir, que esa atención a lo que parece vehicular más

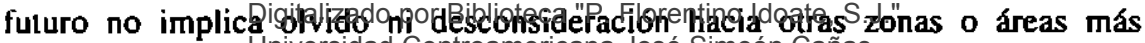
Universidad Centroamericana José Simeón Cañas 
ccrcanas (como pueden ser la increencia curopea o el enorme drama africano). Cristianamente hablando, una oportunidad histórica nunca es un privilegio, sino más bien una responsabilidad mayor.

\section{Que la Iglesia vuelva a ser apostólica}

La apostolicidad de la Iglesia experimenta un serio reduccionismo cuando se la limita a un mero problema jurídico de sucesión lormal. Más aún, históricamente hablando no podría excluirse la hipótcsis de cue esa línea meramente jurídica de sucesión quedara rota en alguno de los varios cismas que afectaron al papado a lo largo del medioevo y de los cuales el más aparatoso, pero no el único, lue el llamado cisma de occidente en el siglo XV. Esas divisiones en la sucesión de Pedro acabaron siendo resuelıas muchas veces por muerte de uno de los pretendientes e inanición de sus seguidores, más que por una clarificación de cuál era la verdadera línea sucesoria.

Pero esta observación -aparenternente lan grave- carece en realidad de importancia desde una noción más completa de la apostolicidad. La apostolicidad meramente formal no basta, como demostraba la antigua discusión sobre el "papa hcreje", el cual dejaba automáticamente de ser papa, por muy jurídicamente que hubiese sido nombrado. La apostolicidad implica —además de la sucesión jurídica - una succsión en la fe, la cual incluye no sólo la doctrina, sino también el seguimiento. Y no sólo seguimiento de Jesús que es sin duda el principal. También hay que decir que los "sucesores de los apóstoles" deben ser "seguidores" de los apóstoles.

\section{Apostolado como misión}

La razón de lo anterior es que el fin primario de la Iglesia es ser enviada, ser misionera, ser "apostólica". Es significalivo que, en el lenguaje eclesiástico, la palabra "apostolado" conecte tanto con los antiguos apóstoles como con esa tarea misionera y evangelizadora que es la razón de ser lundamental de la Iglesia. Ambos significados no pueden separarse. El ministerio eclesial es un ministerio apostólico y no cultual".

También hay que aclarar que, cuando se habla de misión y evangelización, ninguna de estas dos palabras equivale a proselitismo. En cuanto oferta de una "buena noticia" que ha transformado la vida del apóstol, la evangelización consta de servicialidad, anuncio y sacramentalidad. La Iglesia evangeliza siendo servidora del reino y, por tanto, de los hombres. El camino de la Iglesia es el hombre y no al revés"2. La Iglesia evangeliza entonces siendo "sacramento de

11. Cfr. B. Sesbouê, No tengáis miedo, Santander, 1998, pp. 105-107.

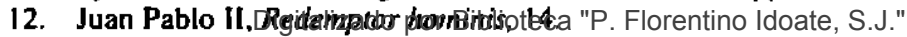

Universidad Centroamericana José Simeón Cañas 
salvación” (LG 1, I) es decir, scñal signilicaliva, no mera imposición nosignilicante, que suple su lalta de significado apelando a la autoridad divina. Sólo después del gesto servicial, siguiendo la enseñanza de Agusı́́n, se añade la palabra y surge así el "sacramenio".

O dicho de otro modo: los cristianos no profesannos que el Logos se hizo "explicación", sino que cl Logos se hizo "carne" y plantó su tienda entre nosoIros (Jn 1, 14). Es decir, la palabra cristiana es ante lodo una palabra "acogedora" antes de ser, y para poder ser, una palabra "explicativa". Y más en una época como la actual. tan consciente de la intrínseca ambigüedad e insuficiencia de todo lenguaje.

Ello hace que, en delerminadas circunstancias, la Iglesia pueda realizar mejor su tarea apostólica a través de lo que cabría llamar "fecundación indirecta" (¡cuántos valores de la modernidad son de origen cristiano aunque no se sepa!) que de la imposición directa.

\section{Apostolicidad y estructuras eclesiásticas}

Acjuí radica hoy uno de los lastres de nuesira lglesia. Porque, si es verdad lo que dice el apartado anterior, se sigue que todas las estructuras de la Iglesia son sólo para su misión y no brolan de un capricho arbitrario de Dios que declara complacerse más en un tipo de estructura (autoritaria, masculina...) que en otra. Parafraseando el dicho de Jesús sobre el sábado. hay que repetir hoy que las esıructuras son para la misión y no la misión para las esıructuras. De ahí que deban buscar ante todo eficacia misionera y coherencia con el anuncio de la Iglesia.

Por ejemplo, es absolutamente làlso, y seguramente herético, afirmar que la Iglesia es monárquica por voluntad de Jesucristo. Que el ministerio de Pedro acabara siendo convertido en una monarquía se debe a la creencia epocal de que la monarquía era la forma más perfecta de gobierno y, por tanto, había de ser la que Dios quería para su Iglesia. Así argumentaba el cardenal Bellarmino. Pero hoy, aquel presupuesto cultural sobre la monarquía ha quedado superado. Y argumentar desde él equivale a sugerir la idea de un Dios arbitrario o ignorante, que no desea lo mejor para su Iglesia ${ }^{13}$.

En consonancia con todo esto ( $y$ hablando ahora desde un punto de vista estrictamente histórico), se afirma hoy que Jesús sólo dejó como estructura eclesial el apostolado, es decir, el grupo de hombres cuya forma de vida fuese la misión. Y dentro de este apostolado, Jesús parece haber dejado también una configuración colegial, en torno al ministerio de Pedro's.

13. Sobre Bellarmino véase la tercera controversia ("De romano pontífice"). Opera, Ed. Vives, 1,461 ss.

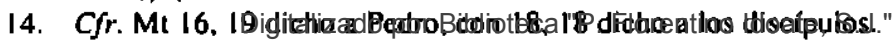

Universidad Centroamericana José Simeón Cañas 
Ahora bien, se ha escrito recientemente que las actuales estructuras de nuestra lglesia más que facilitar obstaculizan o vuclven ineliciente el anuncio eclesial's. ¿Por qué?

Unas veces porque esas estrucluras parecen contradecir el contenido mismo de lo que anuncian: difícilmente puede anunciarse que Dios es amor, y amor en cl hombre (y. por eso, fundamento absoluto de liraternidad), desde unas estructuras primariamente autoritarias, clericalistas, supercentralizadas y que sacralizan más las diferencias y la verticalidad que aquella igualdad por la que "en Cristo Jesús ya no hay varón o mujer, ni señor y esclavo, ni judío o gentil" (Gal 3, 28).

Otras veces porque las comprensibles necesidades de administración, propias de una institución con casi mil millones de miembros, han reducido la tarea evangelizadora y misionera a una tarea burocrática y administrativa. La misión del buen pastor "que conoce sus ovejas y es conocido por ellas" se vuelve así prácticamente imposible. La audacia por la que el pastor se atreve a "dejar las noventa y nueve ovejas" hieles, para salir en busca de la única perdida (cfr. Mt $18,12 s s)$, resulta hoy práclicamente inviable, aunque precisamente hoy la proporción entre noventa y nucve y una debería ser casi invertida. Ocurre también que si algún pastor, cumpliendo el mandato del evangelio. "sale" en busca de la(s) oveja(s) de fuera, suele encontrarse con la queja y la protesta de las ovejas "Tieles" y crea evidenles problemas a los intereses burocrálicos y administrativos.

Por todo ello, podemos decir que el pecado histórico de nuestra Iglesia pucde definirse como una sacralización de las mediaciones, que la vuelven a determinadas mediaciones religiosas del Antiguo Testamento, superadas en el Nuevo Testamento (ver Mateo 18 y 23, 1-12; Hebreos), que oscurecen al Dios de Jesucristo. Quisiéramos subrayar que esa tentación es absolutamente comprensible: los hoinbres tendemos a identificarnos demasiado con nuestras mediaciones, y es Dios y la fidelidad a El por encima de lodo, lo único que acaba sacándonos dolorosamente de ellas. El número doce tenía en la Iglesia del Nuevo Testamento un significado simbólico tan intenso que, según cuenta el libro de los Hechos, lo primero que los apóstoles se sienten llamados a hacer tras la resurrección de Jesús, es recomponer el símbolo de los doce, roto por la desaparición de Judas, y expresión del caŕ́cler de la Iglesia como "nuevo pueblo de Dios"'n. Fueron las necesidades de la misión (y la libertad del Espíritu que suscitó a Pablo fuera de los cauces previstos por la institución) las que obligaron a abandonar aquel número simbólico.

15. J. Martin Velasco, Increencia y evangelizoción, Santander, pp. 148 ss.

16. Como es sabido, el pueblo de Dios del Antiguo Testamento estaba estructurado en torno a las "dQdeitolizas"o por Biblioteca "P. Florentino Idoate, S.J."

Universidad Centroamericana José Simeón Cañas 


\section{Recuperar al "pueblo de Dios"}

Para el nuevo milenio que comienza scrá decisivo que la Iglesia vuelva a estructurarse en torno a los laicos. Laico no signilica "prolano" en oposición a una jerarquía "sagrada", sino simplemente miembro del pueblo de Dios ". El Valicano II definió a la Iglesia como pucblo de Dios y no como potestad sacra. Ello no impide que todo pueblo necesite tener sus ministerios o servicios, tanto para la propia vida comunitaria como para la tarea que lo ha congregado. Pero la designación de esos scrvicios eclesiásticos con vocabulario sacral (sacerdocio, clero, pontílice...) es ajena al Nuevo Testamento.

A su vez, la palabra "clero", que en griego significa suerte, o porción de herencia, designaba en los orígencs a la tolalidad de la Iglesia: ellos son el "pucblo afortunado", el pueblo cuya suerte es Dios o que constituye la "suerte" de Dios. Por eso son "pucblo sacerdotal" (Apo 1. 6; 1Pe 2, 5). Reservar esa palabra sólo para los ministerios eclesiales constituye una recaída en concepciones superadas por el acontecimiento de Cristo, las cuales acaban amenazando la verdadera fraternidad de la comunidad creyente.

$Y$, sin embargo, los responsables de la Iglesia temen hablar de la corresponsabilidad de los laicos, como si ésta no pudiera significar más que irresponsabilidad. Resulta vergonzoso que sólo nos acordemos de la responsabilidad de los laicos a la hora de pedir que pongan una cruz para la Iglesia en la declaración de la renta. Pero quizá la crisis de candidalos al ministerio debe ser vista como un aviso del Espíritu, para que la Iglesia vuelva a encontrar una estructura más concorde con su carácter cristológico y pneumatológico.

Finalmente, en toda esta tarea de reforma estructural hay un punto concreto que merece consideración particular, dada su importancia en el Nuevo Testamento y en la historia de la lglesia. Nos referimos a la configuración del ministerio de Pedro.

\section{Que Pedro vuelva a ser Pedro}

Se ha de superar la figura "gregoriana" de la Iglesia, es decir, la forma de concebir la Iglesia como una diócesis de dimensiones universales, expandida por todo el orbc. La Iglesia universal existe "en y partir de" las iglesias locales (LG 23). (S. Madrigal, "Sal Terrae". octubre 1997, p. 740.)

La imporlancia de Pedro en la lglesia primitiva difícilmente podrá ser ponderada. Además de primer testigo olicial de la resurrección, Pedro fue un factor decisivo de unidad en cuanto aparecieron las inevitables divisiones humanas en cl modo de entender el cristianismo. Armonizó la audacia y la libertad de Pablo

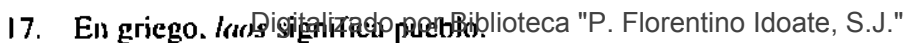
Universidad Centroamericana José Simeón Cañas 
con el afán de fídelidad de los judeocristianos, agrupados en torno a Santiago. Tuvo también la valentía de abandonar una Jerusalén muy centrada sobre sí, pero ajena al futuro, para encaminarse a Roma, centro de la historia de la época, donde acabaría encontrando el martirio. No fue el líder autoritario siempre alabado y exento de error, sino el Pedro débil, capaz de negar al Señor a quien amaba con locura. Pero es muy normal que las primeras comunidades comprendiesen su fe y su capacidad de mediador como verdadera "roca" sobre la que podía descansar la Iglesia ( $c f r$. Mı 16, 17ss).

En seguimiento suyo, mucho más que como "sucesora" suya, la Iglesia de Roma del primer milenio se caraclerizo por una notable capacidad de arbitraje y de mediación, que la fue convirtiendo en fuente de unidad y centro de la comunión eclesial.

La adopción del poder lemporal por los papas, hacia linales del primer milenio, junto a la falsificación de una serie de documentos (Donación de Constantino, Pseudodecretales...), convirtieron "las sandalias del pescador" en una "Iriple corona", que acabó llevando a mil luchas de poder y a una falsificación del ministerio petrino. El "siervo de los siervos de Dios" pasó a ser una especie de "vicedios" en la lierra; y todavía resuenan hoy las palabras escritas hace casi mil años por san Bernardo al papa Eugenio III: "no pareces sucesor de Pedro, sino de Constantino"'t.

Sólo cuando el papa pasó a ser un monarca político se pensó en converir a la Iglesia en una "monarquía", con la lógica resistencia del oriente. Hasta entonces Roma había sido centro de comunión y criterio de fe y de unidad, pero de ningún modo suplantadora de las iglesias locales con sus iniciativas y sus autonomías.

Papas recientes han tenido la audacia de reconocer que Pedro se había convertido hoy en el mayor obstáculo para la unidad, cuando su ministerio es precisamente un ministerio de unidad. Y Juan Pablo II, en un documento reciente, ha pedido a todos los fieles inspiración y ayuda para que el ministerio petrino, sin perder su identidad, vuelva a ser un facior de unidad y se conligure de tal modo que la denominación de "siervo de los siervos de Dios" aparezca como su tílulo más adecuado". Empalmando con lo dicho en el Capítulo I, al hablar del ecumenismo, podemos afirmar que ahí reside uno de los grandes desafíos evangélicos para la Iglesia del tercer milenio.

Hay además mil puntos concretos que pueden ya desde ahora ir comenzando a activar la respuesta a ese desalío. Por ejemplo:

18. De considerarione. lib. 4. III, 6.

19. Ver los númerBjgisglig9dpe

Universidad Centroamericana José Simeón Cañas 
-la clección del obispo de Roma:

-la renuncia al título y al carácter político de jele de Estado, que están en la raíz de tanlos pecados y errores de la Iglesia posterior (y que es algo distinto de la existencia del pequeño estado Vaticano);

- la devolución a las iglesias locales la elccción de sus pastores, de acuerdo con la práctica vigente durante todo el primer milcnio. y que lue defendida y legislada por numerosos papas;

-la supresión del colegio cardenalicio y del título prolundamente pagano de "príncipes de la Iglesia";

-la disponibilidad de los obispos de Roma para saber dimitir a su tiempo como un obispo más:

-la plena igualdad (que debería ir acompañada de una profunda gratitud) en cl trato que la Iglesia da a la mujer;

-la profunda reforma de la curia romana y la plena puesta en vigor de la colegialidad episcopal;

- la supresión de los nuncios apostólicos y de las nunciaturas, dejando que sean los presidentes de las diversas conferencias episcopales los que cuiden de modo particular la relación de las diversas iglesias con el obispo de Roma.

Eslos y otros son puntos en los que la Iglesia católica se juega su fidelidad al cvangelio y su credibilidad ante el inundo, por cuanto, a través de ellos, es como será modelo de una fe que no aparece dictada "por la carne y la sangre", sino por "el Padre que está en los cielos" ( $c f r$. Mı 16, 17). De lodos ellos quizá merece ser destacado el último: la curia romana no debería convertirse en una cuña metida en el colegio apostólico, que separe a papa y obispos, sino más bien estar al servicio del colegio (como consecuencia de que está al servicio del papa, que es inseparable del colegio). Pero algunos documentos últimos (como el del laicado) parecen una reprimenda de la curia a los obispos, como si la colegialidad eclesial se diera entre papa y curia y no entre papa y colegio episcopal. Eso carecería de sentido eclesiológico, sería una praxis no orlodoxa, fruto del miedo y del instinto de conservación.

No nos toca a nosotros concretar más. Somos sólo una voz, en la Iglesia y no pretendemos ser una voz que suplante a otras, sino una voz fiel (y ojalá que profundamente (iel) al Señor de lodos. No una voz de las que acaban imponiéndose por juegos y correlaciones de poder, sino por la verdad que pueda haber en lo que dice, por aquello que recordaba Jesús a los jefes judfos: "si éstos callan hablarán las piedras" (Lc 19,40). Pero deseamos mucho esta recuperación de la auténtica "apostolicidad" de la lglesia, porque crecmos que en ella, y en la unidad de los cristianos, se juega cl cristianismo gran parle de sus posibilidades para el futuro.

Digitalizado por Biblioteca "P. Florentino Idoate, S.J."

Universidad Centroamericana José Simeón Cañas 


\section{Que la Iglesia vuelva a ser santa}

- Sin la hybris de una jerarquía eclesiástica que quiera planificarlo todo y apagar al Espíritu, a ese Espíritu que puede ser molesio, que siempre es nuevo e imprevisible, que es amor, que puede ser duro, que dirige a los hombres y aun a la Iglesia a donde no tenían pensado ir, a lo siempre nuevo y desconocido que, solamente cuando ya existe, se manifiesta como lo que está en amonía con el Espíritu siempre antiguo y siempre nuevo... El Espíritu de Dios... nunca puede ser traducido de forma adecuada, ni totalmente puesto a disposición de la Iglesia, mediante lo que llamamos jerarquía, principios, sacramentos y doctrina (K. Rahner, Escritos de teologia, VII, pp. 86-87).

El Vaticano II habla de la Iglesia como comunidad de la fe, la esperanza y la caridad, o bien como comunidad del Padre, del Hijo y del Espíritu. Cualquiera de estas dos designaciones nos acerca a la primera de las notas del credo, que será la última de nuestro comentario: la santidad de la Iglesia.

El último desafío imposible para la Iglesia del tercer milenio es tratar de cumplir las palabras de Jesús: "ser santa como el Padre celestial" (Mi 5, 48), que Lucas parafrasea como ser "misericordiosa como el Padre" (Lc 6, 36). Porque la santidad de Dios -expresión bíblica de su trascendencia- no consiste en su poder, ni en su fuerza, sino en el amor.

Es normal que esta exigencia nos desborde y nos supere a todos los creyentes. Nadie que conozca de verdad lo que da de sí nuestra pasta humana ( $y$ aún más nuestra pasta social) podrá tomar el pecado de la Iglesia como una razón suficiente para romper con ella. Siguiendo a K. Rahner, deberíamos decir que, ante los pecados de la Iglesia, lo que debemos hacer es reconocer, pero no para condenar, sino para amar. Es lo que viene a decir la suma de estas tres frases del leólogo alemán:

- Si uno realmente es cristiano, si su ojo y su corazón están educados en la implacabilidad del evangelio, ¿podrá —lal vez más que los demás hombres- negar esos pecados, disimularlos o minimizarlos?

- Quizá tengamos (en la condena) un espléndido álibi: nada tenemos que ver con "esa" Iglesia. Estaremos más cerca de nuestros ideales, pero no estaremos más cerca de Dios.

— ¿Por qué no amamos a la Iglesia padeciendo humilde y silenciosamente el escarnio de sus pecados? ${ }^{20}$.

¡Ser misericordiosa como el Padre celestial!... Si Dios es tal como se ha revelado en Jesucristo, la misión de la Iglesia ha de ser antes que nada intentar transparentar a Dios como Jesús, no pretender "defenderlo" y menos por la

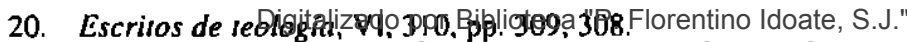


lucrza. Porque siempre que los hombres han pretendido defender a Dios, han corrido el riesgo de defenderse sólo a sí mismos y de acabar matando, "en nombre de Dios", a los enviados de Dios (cfr. Jn 16, 3). Y siempre que han pretendido acaparar el Espíritu en defensa propia. han terminado por apagar y ahogar el Espíritu (cfr. ITes 5, 19). Sólo el esfuerzo por transparentar a Dios resulta evangelizador, porque constituye, por sí mismo, una buena noticia increíble.

Esta inisericordia a Iransparentar se concrela, de cara al futuro inmediato, en los dos últimos desafíos para la Iglesia del tercer milenio: la primacla jesuánica y cristológica de los pobres ( $c f r$. Lc 6 ; Mt $25,3 / \mathrm{ss}$ ), y la conversión evangélica de la autoridad en servicio (cfi: Lc 22).

\section{Transparentar al Dios de los pobres}

No vamos a entrar mucho en el primero de estos dos puntos. Dada su gran imporlancia, ya le dedicamos un cuaderno íntegro de todos los que, a lo largo de este año, han intentado describir los desalíos del tercer milenio. Muy rápidamente añadiríamos sólo un par de observaciones.

Decía José María Castillo en el cuaderno citado que la Iglesia debe perder tolalmente el miedo a los pobres. También el Vaticano II, en su mensaje final al mundo, intentó decir algo de eso. Pucs bien, añadimos ahora que ese miedo se ha puesto en juego muchas veces. a través del uso de la ortodoxia como arma contra los pobres. Lo que queremos decir lo expresa bien gráficamente esta cita hislórica que no constituye un caso aislado. En el tercer concilio de Letrán (II79) se presentaron los valdenses

para ver aprobada la traducción de la Escrilura en lengua vulgar, y su aspiración de radicalismo evangélico: "seguir desnudos al Cristo desnudo". Walter Map, que presidía, obtuvo la condenación de los pobres, haciéndoles caer en error con una auténtica trampa teológica (les preguntó si confesaban a la Madre de Cristo y, tras su asentimiento, les acusó de no reconocer el título de Madre de Dios para María). Es una muestra del abismo que separaba a la élite teológica de estos grupos de radicalismo cristiano"2.

Ese abismo sigue todavía presente en muchos sectores de la Iglesia. No fue aquella la única vez que se ha utilizado lo que los pobres alirman para hacerlos negar aquello que nunca han pretendido negar. Expresiones como "Iglesia de los pobres", "comunidades de base" o "Iglesia popular" nunca pretendieron negar el otro polo (jerárquico) de la Iglesia. Pero sí hubo voces que trataron de desautorizarlas, acusándolas de eso. Exactamente igual a como en los primeros siglos se

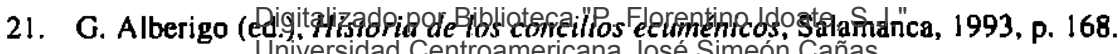


acusaba de negar la divinidad de Jesús a quienes pretendían subrayar su humanidad, o viceversa.

Es pues el momento de afirmar que todo uso de la ortodoxia, como razón contra la causa de los pobres, sólo será una lalsificación de aquélla que no merece más que la advertencia de la carła de Santiago: también los demonios tienen ortodoxia y se estremecen (Sant 2. 19). Esta advertencia está dicha en la carta para aquellos que "ven hambrientos o desnudos a sus hermanos y -pudiendo- no les procuran lo necesario" ( $c f r$. Sanl 2, 14-16).

En segundo lugar, pensamos que sería magnílico si, al comienzo del próximo milenio, la Iglesia universal (y sobre todo las iglesias del primer mundo), en la línea de las palabras de Juan Pablo ll que abrían este cuaderno, examinamos nuestro silencio o connivencia con el holocausto de todos los condenados de la tierra. Una connivencia que nos parece ha sido mayor, y menos reparada, que la que pudo darse en liempo del nazismo frente al holocausto judío. $\mathrm{Y}$ que, en cualquier caso, sigue manteniendo vigente la frase que en aquellas circunstancias acuñó D. Bonhoeffer: "la Iglesia sólo tendrá derecho a entonar el canto gregoriano cuando haya gastado su voz. en lavor de los judíos".

Como en este mundo todos los geslos pueden devaluarse, es poco importante que haya o no una petición pública de perdón, la cual no puede ser reclamada ni impuesta por la presunta víctima, porque entonces ya no termina en reconciliación, sino en victoria de ésta. Lo importante es que penetren en nosotros las palabras de Juan Pablo 1l, que encabezan el presente cuaderno: “icómo callar después de tantas formas de violencia perpetradas incluso en nombre de la fe?". Por eso, ante el jubileo del tercer inilenio, "la Iglesia tiene necesidad de conversión (metanoia) que es... la condición preliminar para la reconciliación con Dios, lanto de las personas como de las comunidades"2?.

Cada Iglesia local debcría concretar después esa conversión en su propia circunstancia. Si se nos permite sugerir un par de gestos globales a este tema, pediríamos, en primer lugar, que no se olvide la enseñanza que recuerda Juan Pablo II: "ante los casos de necesidad no se debe dar preferencia a los adomos superfluos de los templos y a los objetos preciosos del culto divino, al contrario, podría ser obligatorio enajenar estos bienes para dar pan, bebida, vestido y casa a quien carece de ello" (SRS 31).

Otro gesto global, en el que deberían participar todas las iglesias, lideradas por la de Roma. debería ser sumarse denodadamente a lodos los esfuerzos que van a buscar que la entrada en el nuevo milenio suponga el fin radical de la injusta deuda $\mathrm{e}(\mathrm{x})$ terna que ha paralizado durante tantos años a tantos países del lercer mundo.

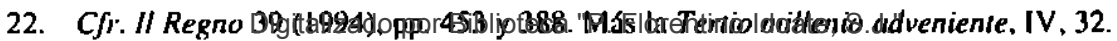
Universidad Centroamericana José Simeón Cañas 


\section{Transparentar al Dios que renuncia a su poder}

Por lo que hace al segundo punto, debe quedar claro -cono ya dijimos al principio- que no alirmamos nada contra la autoridad, ni contra su absoluta necesidad en la Iglesia. Sólo abogamos por una conversión evangélica en el modo de ejercerla. Una conversión a la que también aludió Juan Pablo II en la clausura del sínodo europeo de 1991, cuando pidió perdón "por los testimonios lalaces de quienes, reciamándose de Cristo, no han puesto el poder y la autoridad al servicio de la paz., la justicia y la libertad"'?.

La autoridad es una necesidad de la multiplicidad humana, indispensable para la convivencia y la colaboración. Todas las instituciones anárquicas han acabado escindiéndose o siendo víctimas sin nombre de manipulaciones y de liderazgos ocultos. Dios no pretende que su Iglesia juegue con ventaja en la historia, y respeta csas leyes de nuestra convivencia. No se trata, por tanto, de que la autoridad y el poder de la Iglesia sean por sí mismos teolánicos; pero su necesidad pone de relieve la renuncia de Dios a jugar con ventaja cuando entra en nuestra hisloria.

Pero, aun así y todo, lo que verdaderamente transparenta a Dios no es el poder, sino la comunión de liberlades. Pensar lo contrario para el caso de la Iglesia sería incurrir en una especie de "arrianismo eclesiológico". Por eso, el mismo evangelio, que reconoce la necesidad de la autoridad, aboga decididamente por su radical transformación en servicio. Y sigue resonando el mandamiento de Jesús: "no suceda entre ustedes, como entrc los jefes de las naciones". que actúan autoritariamente y luego reclaınan la alabanza ( $c f r$. Lc 22, 24-26).

La Iglesia tiene la orden de "no acomodarsc a la ligura de este mundo" (Rom 12,2), ni siquiera con la excusa de poder combatirlo mejor. Por eso reza en la plegaria eucarística pidiendo que Dios "la lleve a la perfección por la práctica del amor" y no por el cjercicio del poder. Porque, en el momento en que la Iglesia se acomode a esa figura de este mundo, ya habrá sido vencida por él. Y debemos reconocer que, en este campo, es hoy la sociedad civil la que en muchos lugares da cjemplo de valores evangélicos, en lugar de ser la Iglesia aquella "luz del mundo" (LG 1, 1), que está llamada a ser.

En este contexto es donde cobra su vigencia la dernanda por la "democratización" de la Iglesia a que antes henos aludido. No se trata de una "acomodación a los tiempos", sino de uná obediencia al evangelio. Tampoco tiene sentido disculir si la Iglesia es o no es, o puede ser "una democracia". Debería ser claro que sólo de manera muy analógica puede ser la lglesia comparada a la sociedad civil. Pero ya hemos dicho también que los términos de "comunión" y "sinodalidad", de prolunda raíz eclesial, plantean un problema parecido y unas

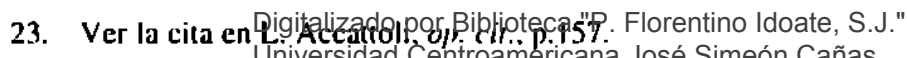


exigencias mayores que la palabra democracia. Y la Iglesia debe sentirse profundamente obligada a que esos términos sagrados no queden en ella tan devaluados y tan falseados como lo está hoy la palabra democracia, en las actuales sociedades civiles de dictaduras económicas y mediáticas.

Digamos, pues, que si la democracia puede caracterizarse por una serie de rasgos como gobierno del pueblo, control del poder, representatividad, división de poderes y Eslado de derecho... muchos de esos términos pueden valer para la Iglesia al menos parcialmente, y otros no. En efecto,

-La Iglesia no es un "gobierno del pueblo", sino de la palabra de Dios; pero es una sociedad de iguales, $y$, por eso, pertenece a la tradición eclesiástica aquel principio que hoy es casi de derecho común: "lo que afecta a todos debe ser tratado y aprobado por todos".

-La Iglesia es, además, una "sociedad de la gracia", y esto va todavía más allá de lo que en las democracias se llama "Esıado de derecho" o "imperio de la ley".

- La Iglesia es una comunidad en la que los pobres tienen la primacía por derecho divino, cosa de la que nuestras democracias formales están tremendamente lejos.

-Pero en la Iglesia pueden tener la misma vigencia que en cualquier sociedad civil algunos principios sociales como el de subsidiariedad y el de división de poderes. Por eso, resulta escandaloso que una Iglesia que defiende esos principios en sus enseñanzas sociales, se sienta dispensada de aplicárselos a sí misma.

Pongamos también un único ejemplo de ese absurdo. Juan Pablo II ha escrito que "la organización de la sociedad organizada en tres poderes (legislativo, ejecutivo y judicial)... refleja una visión realista de la naturaleza social del hombre, [porque] es preferible que un poder esté equilibrado por otros poderes y otras esferas de competencia que lo mantengan en su justo límite". A esta sabiduría humana contrapone el papa la concepción de aquellos totalitarismos que "consideran que algunos hombres... por contacto con las fuentes más prolundas de la conciencia colectiva, están exentos del error y pueden por tanto arrogarse el ejercicio de un poder absoluto" (CA 44). Merece notarse que los argumentos aportados por Juan Pablo II derivan de la misma naturaleza social del hombre (la cual no queda moditicada por el hecho eclesial). ¿Quién podrá pretender entonces que todos esos argumentos no valen para la Iglesia?

Lo mismo valdría del célebre "principio de subsidiariedad" calificado por Juan XXIII como "principio inamovible", y que no vale sólo para las relaciones entre los individuos y los poderes públicos, sino también para las comunidades

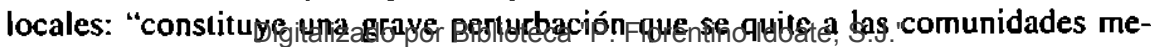


nores o inferiores lo que ellas pueden realizar y conseguir, para dárselo a una instancia más elevada" (MM 53).

Son, además, principios que saldrían fácilmente al encuentro de toda la teología neotestamentaria de las "iglesias locales". Y que en la actualidad, en nuestra Iglesia calólica, brillan por su ausencia...

En este contexto se hace también inevitable una palabra sobre la autoridad docırinal, que es la que ha creado más problemas en los dos últimos siglos. La Iglesia del siglo XX ha estado marcada por tres grandes corrientes: el modernismo, la nouvelle thèologie y la teología de la liberación. Con sus vacilaciones y sus desenloques iniciales, descubricron y recuperaron tres auténticas "fuentes de vida" cristiana: la experiencia religiosa, el carácter de "buena noticia" (o Kerygma) del cristianismo, y la "insuperable dignidad" de los pobres en la Iglesia. Vistos desde la distancia de hoy, escandaliza la reacción de la autoridad frente a ellos, que se redujo a una condena global, falta de todo matiz, y a una persecución cruel de sus representantes. De estos episodios habría que aprender para el siglo que viene. En la Iglesia de Jesucristo, la vigilancia doctrinal no puede hacerse "aplastando la caña quebrada" o "apagando la mecha humeante", ni tratando de "realizar la verdad contra la caridad", en oposición explícita a lo que sugiere el lenguaje de la Escritura (cfr. Is 42, 2; Ef 4, 15).

Podemos concluir, por consiguiente, que tanto la democratización de procedimientos, como la plena igualdad de la mujer y el ejercicio de la crítica son valores que la Iglesia debe aceptar en el próximo milenio, aunque luego deban ser regulados jurídicamente, según casuísticas y circunstancias. Pero de tal modo que esa regulación atienda a salvaguardarlos y no a hacerlos desaparecer como valores.

Si esa regulación transparenta efectivamente al Dios de los pobres y al Dios "rico en misericordia", la Iglesia volverá a ser semillero de esperanza para un mundo tan necesitado de ella.

\section{Conclusión}

En el discurso a los cardenales sobre el jubileo del año 2000, con el que abríamos este cuaderno, decía expresamente Juan Pablo II que "una mirada atenla a la historia del segundo milenio quizá nos permita subrayar otros errores similares o incluso otras culpabilidades". Pensamos que esa mirada al pasado milenio puede ayudarnos, entre otras cosas, a no idolatrar a la Iglesia al amarla.

En efecto; enseñaban los teólogos medievales que en la Iglesia no se puede creer, y que afirmar lo contrario sería idolatría, puesto que la Iglesia es una creatura de esta historia. Creer con el dinamismo de la fe que salva al hombre,

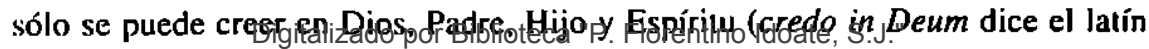


con un sentido dinámico que no tiene nuestro castellano). Y, sin embargo, esa le es intrínsecamente eclesial (credo ecclesiam): de ella brota la aceptación de la Iglesia. Pues, aunque la le sea el aclo más profundo de la persona, nadie puede vivirla individualmente". Al creer en un Dios que es "comunión" (Padre, Hijo y Espíritu) aceplamos que existe una Iglesia integradora, plural, seguidora de Jesús y transparentadora del Padre (es decir, una, católica, apostólica y santa).

De acuerdo con esto, a lo que debe aspirar la Iglesia no es a que los hombres crean en ella de manera lal que desapareciese el riesgo y la entrega de la fe en Dios. El relo decisivo para la Iglesia es vivir profundamente la experiencia del Dios vivo, y ayudar a la gente a que pueda hacer auténticas "experiencias de Dios". que la ayuden a ser creyente en un mundo secularizado. Debe aspirar, por tanlo, a que el Espíritu la trabaje a ella y la vaya conligurando como comunidad de creyentes, para que los hombres puedan encontrar a Dios Padre, Hijo y Espírilu.

Podemos decir, entonces, que la Iglesia es una porque es la Iglesia del Padre, Origen único de todo; que es católica por ser Iglesia del Hijo Recapitulador de todo lo existente; que es santa por ser Iglesia del Espíritu Santificador; y que es apostólica por ser Iglesia en el mundo y para el mundo ( $C S 1,1)$.

Y, cuando decimos que la Iglesia debe aspirar sobre todo a que el Espírilu la trabaje a ella en servicio de los hombres, quisiéramos empalmar este cuaderno con el que publicamos a fines del pasado año sobre el Espíritu Santo, como introducción a todos los cuadernos de este año 1999". Los cristianos -se decía alli- no deben abordar el tercer milenio con la expectativa supersticiosa de acontecimientos esotéricos, ajenos a la densidad de csia historia. Pero sí que pueden orar al Señor para que conduzca a su Iglesia a lo que Juan XXIII deseara como "un nuevo penlecostés".

Al desear un nuevo pentecostés para la comunidad de creyentes, queremos destacar tres rasgos de la narración lucana de la venida del Espíritu:

a) Lucas dice que se produjo "como un vienlo vchemente" (Hech 2, 2), porque el Espíritu es fuerza interior y supone una victoria sobre el miedo, en consonancia con las palabras citadas de Juan XXIII en la apertura del concilio.

b) Añade la imagen de las "lenguas de luego" (Hech 2, 3), que evoca una experiencia de contacto y de contacto con algo que quema. La sensación de haber tocado algo ardiente es una preciosa descripción de la experiencia creyentc en el evangelio.

24. Cfr. J. I. González Faus. “Podemos creer en la iglesia?”. en Sal Terrae. junio de 1998. pp. 465-473.

25. Cfr. J. Vives. "Viento de libertad, luente de vida". Cuadernos Cristianisme i Justicia. No. 83 .

Digitalizado por Biblioteca "P. Florentino Idoate, S.J."

Universidad Centroamericana José Simeón Cañas 
c) Y, finalmente, el Espíritu produjo en seguida la koinonía, la comunión de todos los creyentes de muchos lugares y lenguas. Cada uno se encontraba con los demás "en su propia lengua" (Hech 2,5-8), porque la experiencia de la fe no cambia la identidad del creyente, sino que la plenifica, aunque tenga a veces que "quemarla" y zarandearla para purificarla.

Ojalá nuestras palabras hayan nacido impulsadas por esa triple pretensión. Teológicamente hablando, hay en la Iglesia una gran libertad para la palabra audaz, dicha desde el evangelio. Pero esa palabra no pretende acusar (¿quién podría acusar a aquellos a quienes Dios perdona?), sino más bien "idealizar", es decir, marcar lo mucho que todavía nos queda por recorrer para estar a la altura del Espíritu de Dios. Si nosotros no reconocemos nuestros defectos con la alegría del perdón, otros nos los echarán en cara como acusación.

Sólo desde esta óptica nos atrevemos a presentar estas líneas a toda la comunidad de fieles, a todos los hombres y mujeres religiosos y a todos los de buena voluntad. A todos ellos porque, a pesar del lastre inimaginable de lo que Pablo llama "nuestra carne" (y que no es propiamente la dimensión material del hombre, sino su curvatura egoísta, pecadora e incapaz de amar), a pesar de eso, todos estamos llamados a ir trabajando por csa nueva humanidad, por esa hombría perfecta ( $c f r$. Ef, 4,13 ) en la que Dios "recapitula todas las cosas en su Ungido", y en la que el resucitado es dado a la Iglesia no para que ella se lo apropie y disponga de él en beneficio propio, sino para que vaya plenificándolo totalmente en todo ( $c f r$. Ef 1,10 y 23). La institución eclesial sabe así que ella no es el centro de la Iglesia y de la comunión creyente, sino servidora de ellas: el único centro de la fe es Cristo con el don de su Espíritu y la comunidad que crea la fe en ellos. Los cristianos debemos proclamar que la alegría que da esa fe compartida en Iglesia, es mucho mayor que todas las deficiencias que hemos lamentado. Por eso es la misma institución la que pide para sí, y reza estas palabras con las que deseamos concluir:

-Que tu Iglesia, Señor, sea un recinto de verdad y de amor, de libertad, de justicia y de paz, para que todos encuentren en ella un motivo para seguir esperando...

-Que todos los miembros de la Iglesia sepamos discernir los signos de los tiempos y crezcamos en fidelidad al evangelio. Que nos preocupemos de compartir en la caridad las angustias y las tristezas. las alegrías y las esperanzas de los hombres, mostrándoles asł el camino de la salvación (Plegaria eucarística $V$, b y c). 